\title{
Hydrograph-Based Hydrologic Alteration Assessment and Its Application to the Yellow River
}

\author{
Z. Z. $\mathrm{Ma}^{1}$, Z. J. Wang ${ }^{1, *}$, T. Xia ${ }^{1}$, C. J. Gippel ${ }^{2}$, and R. Speed ${ }^{3}$ \\ ${ }^{1}$ State Key Laboratory of Hydroscience and Engineering, Tsinghua University, Beijing 100084, China \\ ${ }^{2}$ Fluvial Systems Pty Ltd, Stockton, New South Wales, NSW 2295, Australia \\ ${ }^{3}$ Okeanos Pty Ltd, Brisbane, QLD 4000, Australia
}

Received 23 April 2012; revised 12 April 2013; accepted 19 August 2013; published online 18 March 2014

\begin{abstract}
With the evolution of society and increasing population, increasing amounts of water resources are being developed to support the needs for such commodities as water and energy, but this development has significantly changed the hydrologic processes in many rivers from their natural state. In this paper, a hydrograph-based hydrologic alteration assessment (HHA) is proposed to describe the hydrologic regime with the attributes of biodiversity and river health, and to assess the hydrologic regime alteration impacted by four main reservoirs in seven sections in the trunk of the Yellow River, and also a comparison to IHA-RVA. The results indicate the following: (1) the hydrologic regimes in the Yellow River have experienced significant changes, from upstream to downstream, corresponding to the construction and operation of the reservoirs; (2) the Sanmenxia reservoir in middle reach has a relatively smaller influence on the hydrologic regime than the largest reservoir of Longyangxia in upper reach; and the hydrologic alteration in the midstream reach is less than in the upstream and downstream reaches; and (3) HHA and IHA are both suitable for assessing hydrologic regime alteration, but HHA is benefit to diagnose the regulation of reservoirs, and IHA places more significance than HHA on the extreme mean flow, which is an advantage in small-discharge regimes and a disadvantage in large-discharge regimes in terms of biodiversity and river health.
\end{abstract}

Keywords: hydrologic regime alteration, flow event, HHA, IHA-RVA, the Yellow River

\section{Introduction}

The natural flow regime plays an important role in supporting biodiversity and the integrity of river ecosystems (Richter et al., 1996; Poff et al., 1997; Yang et al., 2008; Assani et al., 2010). Over time, aquatic organisms have evolved and adapted to the intra- and inter-annual variation of river flows. However, human activities, such as the construction of dams and the withdrawal of water from river channels, can significantly alter the flow regime. These changes in the flow regime can result in the loss of river ecosystem functions (Stanford et al., 1996; Poff et al., 1997; Gippel, 2001; Pegg et al., 2003; Richter et al., 2003; Lytle and Poff, 2004; Choi et al., 2005; Magilligan and Nislow, 2005; Richter et al., 2006). To reduce the impact of these changes and restore the biodiversity and ecosystem integrity, alterations in the river hydrologic characteristics should be fully understood.

Globally, many multivariable index systems and evaluation methods have been proposed to evaluate hydrologic alte-

\footnotetext{
* Corresponding author. Tel.: +86 10 62782021; fax: +86 1062796971.

E-mail address: zj.wang@tsinghua.edu.cn (Z. J. Wang).
}

ISSN: 1726-2135 print/1684-8799 online

(C) 2014 ISEIS All rights reserved. doi: 10.3808/jei.201400252 ration (Richter et al., 1996; Richter et al., 1997; Growns and Marsh, 2000; Olden and Poff, 2003; Black et al., 2005; Suen, 2006; Chang et al., 2008; Shiau and Wu, 2008; Chang et al., 2009). Among these methods, the Indicators of Hydrologic Alteration (IHA) and Range of Variability Approach (RVA) are among the most commonly used methods. The IHA relies on 33 hydrologic parameters (Richter et al., 1996). Richter et al. $(1997,1998)$ subsequently proposed the RVA as an evaluation method to measure hydrologic changes. The RVA assesses hydrologic alteration based on the frequency differrence between the pre- and post-impact periods (phases). With its complete set of indicators and sound mechanisms, the IHA-RVA is widely used all over the world. For instance, this method was used by Galat and Lipkin (2000) in the Missouri River of America, highlighting changes to the flow regime after mainstream impoundment. Focusing on the Peinan Creek of Taiwan, Shiau and Wu (2004) demonstrated that the low-flow regime was easily affected by the Peinan weir flow diversion and that the degree of hydrologic alteration was linked to the degree of flow diversion. Magilligan and Nislow (2005) used IHA-RVA to assess the hydrologic condition of 21 sites across the United States and found that dams made a remarkable impression on the flow regime, especially on the minimum and maximum flows over different periods. At the Bengbu Sluice in the middle Huai River of China, Hu et al. (2008) used IHA-RVA to demonstrate that the sluice had a 
strong negative influence on the eco-hydrologic conditions, especially in the dry seasons during low-flow events. Focusing on the Han River, Kim et al. (2011) analyzed the changes in extreme weather events and the associated flow regime in both the past and future using the IHA-RVA method combined with a climate model and hydrologic model. And focusing on Lijin (LJN) in the lower Yellow River of China, Yang et al. (2011) demonstrated that the hydrologic features changed noticeably after 1984 .

Althouth IHA-RVA has been widely used as a practical and effective approach to evaluate the alteration of the flow regime, there are still several limitations of this method. First, the numbers of IHA indices are big enough but from mean annuals values that do not fully represent the variation of flow process events. Flow process events, such as high flow pulses in spring and summer, often serve as ecological "bottlenecks" for aquatic species' growth and reproduction (Poff et al., 1997). The hydrographic process events are also sensitive to annual values at particular times for the ecosystem. Second, IHA-RVA results cannot easily guide reservoir operation (Yang et al., 2011), as they present frequency differences that are not practical for the operation of the water infrastructure. Third, the validity of the hydrologic alteration assessment is highly dependent on the availability of sufficient long-term stream gauge records (Richter et al., 1998; Yang et al., 2008).

This paper has attempted to improve the hydrologic indices by a method considering both mean flows and flow events based on a sound hydrograph process pattern, termed the hydrograph-based hydrologic alteration assessment $(\mathrm{HH}-$ A), to highlight the importance of full-flow events in a river's eco-hydrology and also to reduce the 33 indicators of IHA to the 25 indicators of HHA via the pattern shaping of hydrograph seasonal features. By applying the method to the Yellow River of China, the impact of major dams on the hydrologic regime of the mainstream of the Yellow River is identified, which may provide a valuable and practical framework to improve the management and regulation of water resources in the Yellow River.

\section{Method}

\subsection{Seasonal Characteristics of the River Hydrologic Re- gime and Its Ecological Influence}

A river flow regime involves a seasonal variability associated with the natural intra-annual climatic variation (Chen et al., 2006). Generally, an annual flow can be divided into three hydrologic seasons by flow events: the dry season, flood season, and rising-water season. During the dry season, the flow and water levels are both very low and the runoff is composed mainly of the base flow. During the flood season, the runoff is very high and floods are typical. During the rising-water season, the river flow will increase gradually from the dry season to the flood season. In China, the dry season typically corresponds to later autumn, winter, and early spring, and the flood season corresponds to later spring, summer, and early autumn. The rising-water season defined in this paper refers to spring and early summer, which are the significant times for river biosystem reproduction stimulated by high-flow-pulse events.

Some approaches have indicated that the seasonal characteristics of the river flow regime are the foundation of species histories, ecological processes, and the productivity of aquatic and riparian communities (Bayley, 1988; Naiman et al., 2008; Carlisle et al., 2010). During the flood season, flood events maintain the shape of the river channel, improve the connectivity of the river channel with riparian wetlands and pools, structure diverse habitats in the channel and connected floodplains, and transfer nutrients to the down-stream (Junk et al., 1989; Richter et al., 1996; Poff et al., 1997; Bejarano et al., 2010; Opperman et al., 2010). During the dry season, the lower water level and flow allow local plants to survive in floodplains and riparian wetlands but harm invasive species that cannot tolerate drought stresses and die as a result (Bayley, 1988; Bunn and Arthington, 2002). During the transition season, aquatic organisms are active and breeding; for instance, fishes begin to spawn in response to signals associated with the increased water level and flow pulse. At the same time, a high flow pulse flushes away pollutants and maintains appropriate salinity at the estuary, leading to normal water quality conditions (Bayley, 1988; Richter et al., 1996; Bunn and Arthington, 2002).

\subsection{HHA Indicators}

Based on seasonal features, the hydrologic regime can be described by summarizing the characteristics of the typical flow events in different hydrologic seasons. In this paper, such fundamental characteristics as magnitude, frequency, duration, rise rate, and fall rate (Richter et al., 1996; Poff et al., 1997; Assani et al. 2010) are also chosen as indicators and combined with each type of flow event. The characteristic of timing is not included separately because the typical flow events used are already defined based on their occurrence during a particular hydrologic season in a year and thus incorporate elements of timing. Additionally, the primary feature of drought events is that the flow discharge is consistently below a certain threshold. The rate of change of hydrologic conditions is less important than the other three indicators. Thus, magnitude, duration, and frequency are chosen to represent the characteristics of the drought events. Furthermore, the mean monthly flow provides a general measure of habitat availability or suitability (Richter et al., 1996), and therefore, the mean monthly flows for 12 months are also included in the index. Thus, there are 25 indicators in total, which are divided into four groups: mean monthly flow, high-flow-pulse event in rising-water season, flood event in flood season and drought event in dry season, and their relationship to the ecology, as shown in Table 1 . The calculation methods for each indicator are introduced in Table 2. Because the proposed indices represent the entire hydrologic process over one year to assess the hydrologic alteration based on the hydrograph patterns of the river, we call it the hydrograph-based hydrologic alteration assessment (HHA). 
Table 1. Indicators Used in HHA

\begin{tabular}{|c|c|c|}
\hline Groups & Indicators & Ecological Influences* \\
\hline $\begin{array}{l}\text { Mean monthly } \\
\text { flow }\end{array}$ & $\begin{array}{l}1-12^{* *} \\
\text { Mean value of each calendar month }\end{array}$ & $\begin{array}{l}\text { Provide an adequate habitat and appropriate water level for aquatic organisms } \\
\text { Maintain a soil moisture sufficient for floodplain plants } \\
\text { Provide drinking water and food for terrestrial animals } \\
\text { Influence water temperature, oxygen levels, and photosynthesis in the water body }\end{array}$ \\
\hline $\begin{array}{l}\text { High-flow-pulse } \\
\text { event }\end{array}$ & $\begin{array}{l}\text { For each high-flow-pulse event: } \\
\text { 13. Peak value } \\
\text { 14. Duration } \\
\text { 15. Average rise rate } \\
\text { 16. Average fall rate } \\
\text { For each year: } \\
\text { 17. Frequency of high-flow-pulse event }\end{array}$ & $\begin{array}{l}\text { Stimulate the migration and spawning of fish } \\
\text { Maintain habitat continuity between near-shore/estuarine and freshwater habitats } \\
\text { Replenish/maintain water in river-associated wetlands and backwaters } \\
\text { Remove pollutants in the water channel } \\
\text { Maintain appropriate salinity at estuary }\end{array}$ \\
\hline Flood event & $\begin{array}{l}\text { For each flood event: } \\
\text { 18. Peak value } \\
\text { 19. Duration } \\
\text { 20. Average rise rate } \\
\text { 21. Average fall rate } \\
\text { For each year: } \\
\text { 22. Frequency of flood event }\end{array}$ & $\begin{array}{l}\text { Shape the physical character of the river channel } \\
\text { Improve the connectivity of the river channel with wetlands and pools } \\
\text { Structure diverse habitats in the channel and connected floodplains } \\
\text { Transfer additional nutrients to the downstream } \\
\text { Recharge the floodplain water table } \\
\text { Maintain the balance of species in aquatic and riparian communities } \\
\text { Remove foreign species }\end{array}$ \\
\hline Drought event & $\begin{array}{l}\text { For each drought event: } \\
\text { 23. Duration } \\
\text { 24. Average flow } \\
\text { For each year: } \\
\text { 25. Frequency of drought event }\end{array}$ & $\begin{array}{l}\text { Supply suitable water and soil conditions for the growth of certain floodplain } \\
\text { plants } \\
\text { Purge invasive species } \\
\text { Concentrate prey in limited areas to benefit predators }\end{array}$ \\
\hline
\end{tabular}

Table 2. Calculation Methods for HHA Indicators

\begin{tabular}{ll}
\hline Indictor & Calculation Method \\
\hline Peak value & Maximum daily discharge during a high-flow-pulse event or flood event \\
Duration & Number of days from the beginning to end of a flow event \\
Average fall rate & Mean of all positive differences between consecutive daily discharges during a high-flow-pulse event or flood event \\
Average fall rate & Mean of all negative differences between consecutive daily discharges during a high-flow-pulse event or flood event \\
Frequency & Number of a specific type of flow event each year \\
Average discharge & Mean of all daily discharges during a drought event \\
\hline
\end{tabular}

Compared to IHA indicators, HHA calculates the indicators for the typical flow event in each hydrologic season based on a standard hydrograph process. For example, once the flow on any given day exceeds a specified threshold, it will be classified as a high pulse in IHA-RVA; in HHA, only daily flows greater than the individual day's threshold are classified as high-flow-pulse events and flood events. The individual flow thresholds depend on the standard flow seasonal features, which differ in different periods of a year. Moreover, all flow differences between consecutive days are used to calculate the rates of flow changes in IHA, which is a general annual value. In contrast, the rates of flow changes for each flow event are calculated separately in HHA, yielding seasonal values.

\subsection{Assessment of Hydrologic Alterations using HHA}

Similar to the pairing of RVA with IHA, a comparable method is introduced to assess the alteration by comparing the
25 indicators of HHA for the pre- and post-development periods.

First, the hydrologic record is split into two phases. The earlier period of the hydrologic regime, with little or limited human interference, is defined as the pre-development period. The initial water storage date of a reservoir, the initial division date of a water division project, or the inflection point of water withdrawal from the river can typically be taken as the point at which the record should be split.

Then, two statistical parameters, the mean value and the coefficient of variation, are calculated for each indicator in the different phases (Richter et al., 1996). The mean value $(\bar{x})$ represents the central tendency of the indicator, and the coefficient of variation $(\mathrm{Cv})$ measures the degree of dispersion of indicator values.

Generally, the deviation ratio is used to measure the relative difference between two variables. For each of the 25 in- 
dictors listed in Table 1, the deviation ratio between the preand post-development periods in both the mean and $C v$ is expressed as follows:

$v_{i}^{j}=\frac{x_{i}^{j}-x_{0 i}^{j}}{x_{0 i}^{j}}(j=1,2 ; i=1,2, \ldots, 25)$

where $v_{i}^{j}$ is the $j$ th statistics parameter deviation ratio of the $i$ th hydrologic indicator $\left(v_{i}^{j} \geq-1\right) ; j=1$ indicates that the statistics parameter is the mean value; $j=2$ indicates that the statistics parameter is $C v$; and $x_{i}^{j}, x_{0 i}^{j}$ are the $j$ th statistics parameter values of the $i$ th hydrologic indicator for the postand pre-development periods, respectively $\left(x_{i}^{j}, x_{0 i}^{j} \geq 0\right)$.

The deviation ratios are normalized to grade the degrees of deviation and compare them between different indicators or sites. The normalized result should be positively correlated with the deviation ratio and can reflect both the magnitude and direction (positive or negative) of the deviation. In our research, the Tan-sigmoid function, which is widely used as a transition function in the normalization of artificial neural networks (Kurup and Dudani, 2002; Hamed et al., 2004; Malinova and Guo, 2004; Lin and Wang, 2008; Bashir and El-Hawary, 2009), is used as the normalization function as follows:

$d_{i}^{j}=\frac{1-\exp \left(-a v_{i}^{j}\right)}{1+\exp \left(-a v_{i}^{j}\right)}$

where $d_{i}^{j}$ is the alteration degree of the $j$ th statistics parameter for the ith hydrologic indicator $\left(-1<d_{i}^{j}<1\right)$ and the value of $a$ is set to 3 . The function above is applied for the situation in which a specific type of flow events occurs during both the pre- and post-development periods. Otherwise, if a certain type of flow event was absent during the pre-development period but appears during the post-development period, the degrees of alteration of the related indicators are set as 1 . If the flow events appeared during the pre-development period but disappeared during the post-development period, the degrees of alteration of the related indicators are set as -1 .

Based on the above normalization method, the degree of alteration for the statistics parameters ranges from -1 to 1 $\left(-1 \leq d_{i}^{j} \leq 1\right)$. A positive $d$ indicates that the statistical parameter becomes larger after impact; whereas a negative $d$ indicates that the statistics parameter is smaller after impact. Similar to the RVA method (Richter et al., 1998), the range of $\left|d_{i}^{j}\right|$ is divided into three equal intervals, namely, low alteration $[0,0.33]$, moderate alteration $(0.33,0.67)$, and high alternation $[0.67,1]$.

The mean value of all $\left|d_{i}^{j}\right|$ is used as the overall degree of hydrologic alteration; that is,

$D_{T}=\frac{1}{50} \sum_{i=1}^{25} \sum_{j=1}^{2}\left|d_{i}^{j}\right|$

\section{Study Area and Data Processing}

\subsection{Study Area}

The Yellow River is the second longest river in China, with a drainage area of $752,000 \mathrm{~km}^{2}$ and a length of 5,464 km. The Yellow River originates from the Qinghai-Tibet Plateau in the far west of China and drains into the Bohai Sea in the east, as shown in Figure 1. The river basin is mostly arid and semiarid, with a mean annual surface runoff of $58 \times 10^{9} \mathrm{~m}^{3}$, which accounts for only $2 \%$ of the total runoff of the entire country (Wu et al., 2008). The Yellow River basin is traditionally divided into the upper, middle and lower reaches by above Hekou (HK), Hekou to Huayuankou (HYK), and below HYK. By the end of 2003, more than 2,600 reservoirs with a total capacity of $61.7 \times 10^{9} \mathrm{~m}^{3}$ had been constructed in the Yellow River Basin, performing significant functions in flood control, water supply, hydro-power generation, and sediment deposition. The four largest reservoirs along the main course of the Yellow River are considered the most influential: the Longyangxia (LYX), Liujiaxia (LJX), Sanmenxia (SMX), and Xiaolangdi (XLD) (YRCC, 2000), listed in Figure 1 and Table 3.

The natural flow regime of the Yellow River shows a discernable seasonal variability, as shown in Figure 2, indicating the gauged daily discharge in 1952 at HYK section on the lower Yellow River. This regime was adopted as the natural flow regime, a standard hydrograph process representing the limited human interference with the flow regime prior to 1952.

The operation of reservoirs, together with changes in rainfall-runoff and increasing water withdrawals from the river, has changed the flow regime significantly. The lower reaches of the Yellow River suffered from frequent no-flow; that is, dry-up events occurred from 1972 until 1999 (Liu and Zhang, 2002). During the 1990s, the river was drying up every year in the lower reach for periods lasting up to 272 days and extending as long as $700 \mathrm{~km}$. This significant alteration of the hydrologic regime may result in substantial degradation of the river ecosystem. Therefore, assessing the hydrologic alteration, which is closely connected to water resource management and ecology, is the initial and basic issue in auditing the ecological situation and providing practical guidance for adjusting reservoir regulation to reduce such negative effects.

\subsection{Data}

The daily mean discharge data from seven gauging sections, also known as the evaluation sections, along the mainstream of the Yellow River were analyzed for hydrologic alteration assessment. The gauges and sections are Lanzhou (LZ$\mathrm{H})$, Shizuishan (SZS), Toudaoguai (TDG), Longmen (L- MN), Tongguan (TGN), HYK, and LJN, as shown in Figure 1. 


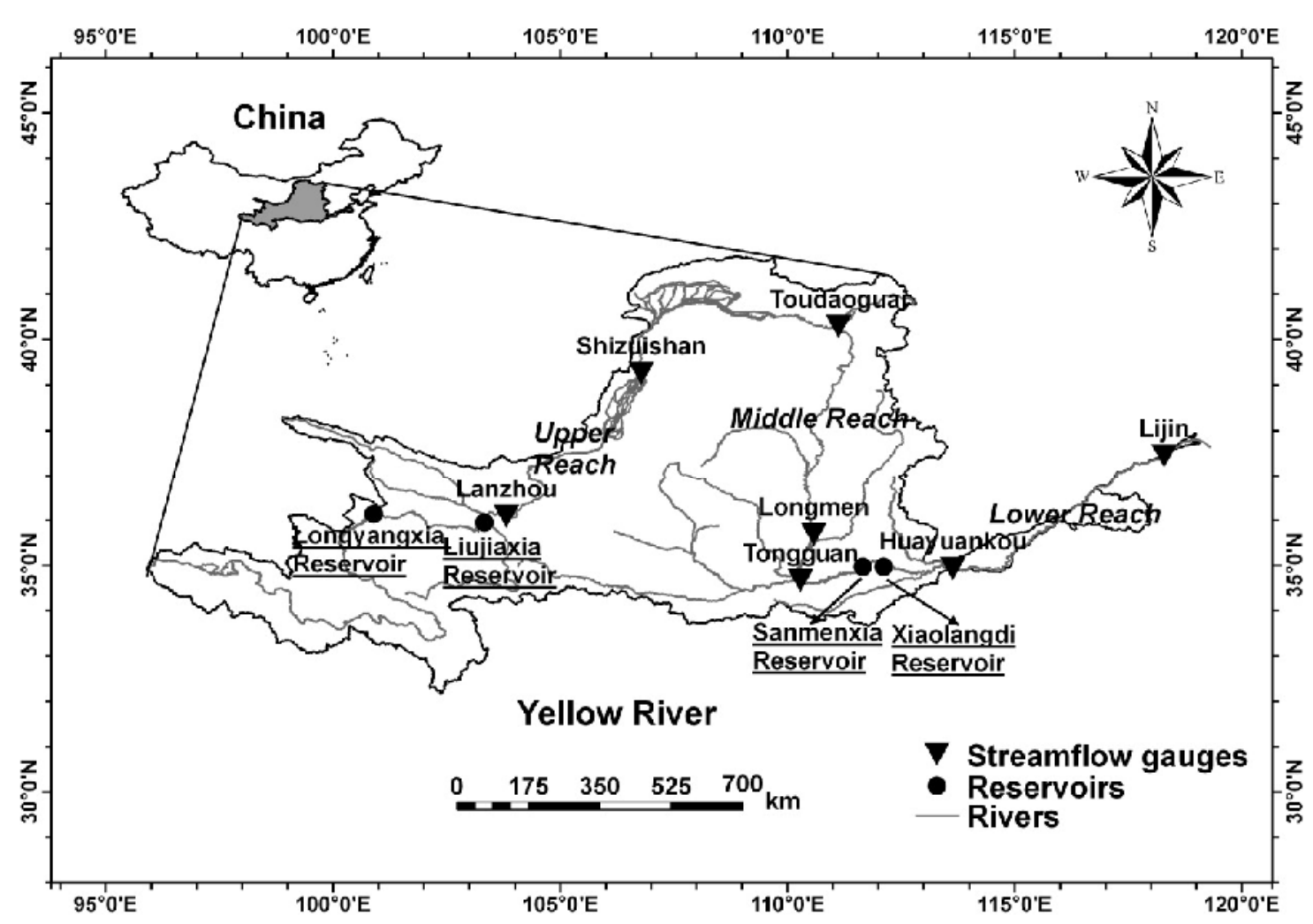

Figure 1. Map of the Yellow River basin and location of case reservoirs and sections.

Table 3. Information on the Largest Reservoirs in the Mainstream of the Yellow River

\begin{tabular}{llll}
\hline Reservoir & $\begin{array}{l}\text { Initial water } \\
\text { storage date }\end{array}$ & $\begin{array}{l}\text { Total capacity } \\
\left(\times 10^{8} \mathrm{~m}^{3}\right)\end{array}$ & Reach \\
\hline Longyangxia & January 1986 & 247.0 & Upper \\
Liujiaxia & January 1968 & 57.0 & Upper \\
Sanmenxia & September 1960 & 103.1 & Middle \\
Xiaolangdi & January 1999 & 126.5 & Middle \\
\hline
\end{tabular}

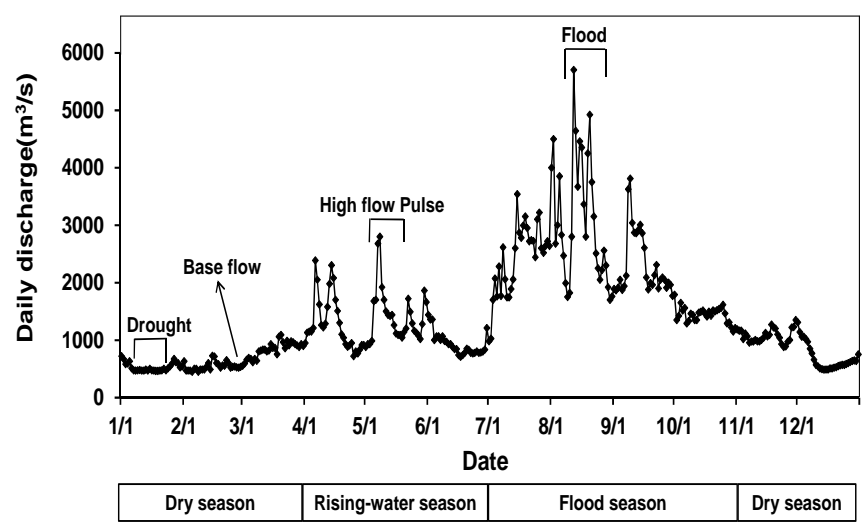

Figure 2. Gauged daily discharge and seasonal definition at HYK in the lower Yellow River in 1952.

The hydrologic records were obtained from the Hydrology Bureau of Yellow River Conservancy Commission (YR-
CC) of China. The historical flow series were split into either three or four periods according to the major phases of regulation, as shown in Table 4. Period 1 is the pre-development period for each section. The degree of alteration is calculated by comparing the indicators in Period 1 with the subsequent periods. The year when a major dam began to store water (signaling the start of a new regulation phase) is not included in the analysis.

\subsection{Identification of Flow Events}

The features of flow events are characterized by separating them from the flow record and then undertaking statistical description (Gippel et al., 2011). Based on the seasonal characteristics of the hydrologic regime and on previous research (Liu and Zhang, 2002; Jiang et al., 2010), the risingwater season is from April to June and the flood season is from July to October. The dry season is defined as the period from November to March. The high-flow-pulse events, flood events, and drought events are identified in each of the above hydrologic seasons. For each section and season, flow events are only considered if they exceed the seasonal threshold.

The method used to separate flow events is based on Gippel et al. (2011). In this method, the base flow is analyzed first to establish the threshold, including calculating the median base flow for each month and setting the lowest or highest seasonal value as the threshold for a drought event or high-flow-pulse event. 
Table 4. Periods and Phases of Record for the Gauging Sections Used in this Analysis

\begin{tabular}{|c|c|c|c|c|c|c|}
\hline \multirow{2}{*}{$\begin{array}{l}\text { Regulation } \\
\text { phase }\end{array}$} & \multicolumn{2}{|l|}{ Period 1} & \multicolumn{2}{|l|}{ Period 2} & \multirow{2}{*}{$\begin{array}{l}\text { Period } 3 \\
\text { Post-Longyangxia }\end{array}$} & \multirow{2}{*}{$\begin{array}{l}\text { Period } 4 \\
\text { Post-Xiaolangdi }\end{array}$} \\
\hline & Pre-Liujiaxia & Pre-Sanmenxia & Post-Liujiaxia & Post-Sanmenxia & & \\
\hline $\mathrm{LZH}$ & $1949-1967$ & & 1969-1985 & & $1987-2000$ & \\
\hline SZS & 1950-1967 & & 1969-1985 & & 1987-2000 & \\
\hline TDG & 1952-1967 & & 1969-1985 & & $1987-2000$ & \\
\hline LMN & $1952-1967$ & & 1969-1985 & & 1987-2000 & \\
\hline TGN & 1952-1967 & & 1969-1985 & & $1987-2000$ & \\
\hline HYK & & 1949- 1959 & & 1961-1985 & 1987-1998 & $2000-2008$ \\
\hline LJN & & 1950-1959 & & 1961-1985 & 1987-1998 & 2000-2008 \\
\hline
\end{tabular}

- $\quad$ Drought event: The threshold of the drought events $\left(Q_{\mathrm{d}}\right)$ is set as the lowest seasonal value of the median base flow in the pre-development period.

- High-flow-pulse event: The threshold of high-flow-pulse events $\left(Q_{\mathrm{p}}\right)$ is the highest seasonal value of the median base flow during the pre-development period. During the rising-water season, the surface flow is increasing and the base flow is decreasing. To guarantee the typicality of the high flow pulse separated from the flow record, the Base Flow Index (BFI) is introduced as another requirement in the separation of high-flow-pulse events. The BFI is the ratio of the base flow to the total flow; $\mathrm{BFI}=1$ when the flow is all base flow and 0 when the flow is all storm flow. In this study, BFI $\geqslant 0.9$ is used to separate highflow-pulse events. That is, the discharge of a high-flowpulse event should be larger than $Q_{\mathrm{p}}$, and the BFI of a high-flow-pulse event should be more than 0.9.

- Flood event: Storm flow is the main component of runoff during the flood season. Flows can be described using traditional flood frequency analysis, which predicts the return interval of events of a given magnitude (Gordon et al., 2004). The threshold of flood events $\left(Q_{\mathrm{f}}\right)$ is the lowest seasonal value of the median flow during the predevelopment period.

The thresholds for the three flow events in each section are listed in Table 5.

Event independence must be considered when separating flow events (Gippel et al., 2011). In this study, event independence is defined as requiring a minimum of five days between instances when the discharge exceeds the threshold.

Table 5. Thresholds for the Three Types of Flow Events at Each Section $\left(\mathrm{m}^{3} / \mathrm{s}\right)$

\begin{tabular}{llll}
\hline Section & $\mathrm{Q}_{\mathrm{p}}$ & $\mathrm{Q}_{\mathrm{f}}$ & $\mathrm{Q}_{\mathrm{d}}$ \\
\hline LZH & 465 & 1,670 & 210 \\
SZS & 350 & 1,655 & 180 \\
TDG & 280 & 1,200 & 155 \\
LMN & 365 & 1,445 & 175 \\
TGN & 610 & 1,970 & 310 \\
HYK & 575 & 2,240 & 230 \\
LJN & 490 & 2,040 & 170 \\
\hline
\end{tabular}

\section{Results and Discussion}

\subsection{Impact of Reservoirs on the Hydrologic Regime}

Of the four largest reservoirs on the main course of the Yellow River, two are located in the upper part of the upstream and the other two are located in the lower part of the midstream. The impacts of reservoirs on the hydrologic regime can be addressed by assessing the hydrologic alteration at $\mathrm{LZH}$, which is the nearest section to the upper two reservoirs of LYX and LJX, and at HYK, which is the nearest section to the two downstream reservoirs of SMX and XLD. The results from LZH and HYK are shown in Figures 3 and 4, respecttively.

(1) Impacts of Liujiaxia operation

As shown in Figure 3(a), the regulation of Liujiaxia mostly influences the drought events and monthly flow processes. The change in drought events at LZH is most notable after the Liujiaxia began to function. The results indicate that the frequency of drought events was 0.16 pre-Liujiaxia but never occurred after the regulation of Liujiaxia. In other words, no droughts have occurred at LZH during the post-Liujiaxia period. These results are consistent with previous research by Zhang (2009). Influenced by the reservoir's regulation, the monthly mean flows decreased during the flood season but increased during the dry season and rising-water season, indicating that the regulation of the Liujiaxia reservoir has resulted in a "flattening" of the hydrograph in the LZH section. The $C v$ of the high-flow-pulse event indicates negative alteration, meaning that pulse events have become more concentrated compared to the pre-Liujiaxia period.

\section{(2) Impacts of Longyangxia-Liujiaxia joint operation}

Figure 3(b) indicates that drought events remain absent with the joint regulation of Longyangxia and Liujiaxia. Compared to the post-Liujiaxia and pre-Longyangxia periods, the $C v$ of each high flow pulse still exhibits a negative alteration, although the extent of the alteration is increased. However, the $C v$ of flood events exhibits a positive alteration, mainly due to the large storage capacity of the Longyangxia reservoir. During the rising-water season, to follow the reservoir regulation rules, the reservoir stores most of the high flows to keep the water near the active level, reducing the variability and the number of pulses. Moreover, the reservoir must retain the capacity to store large floods during the flood season so 

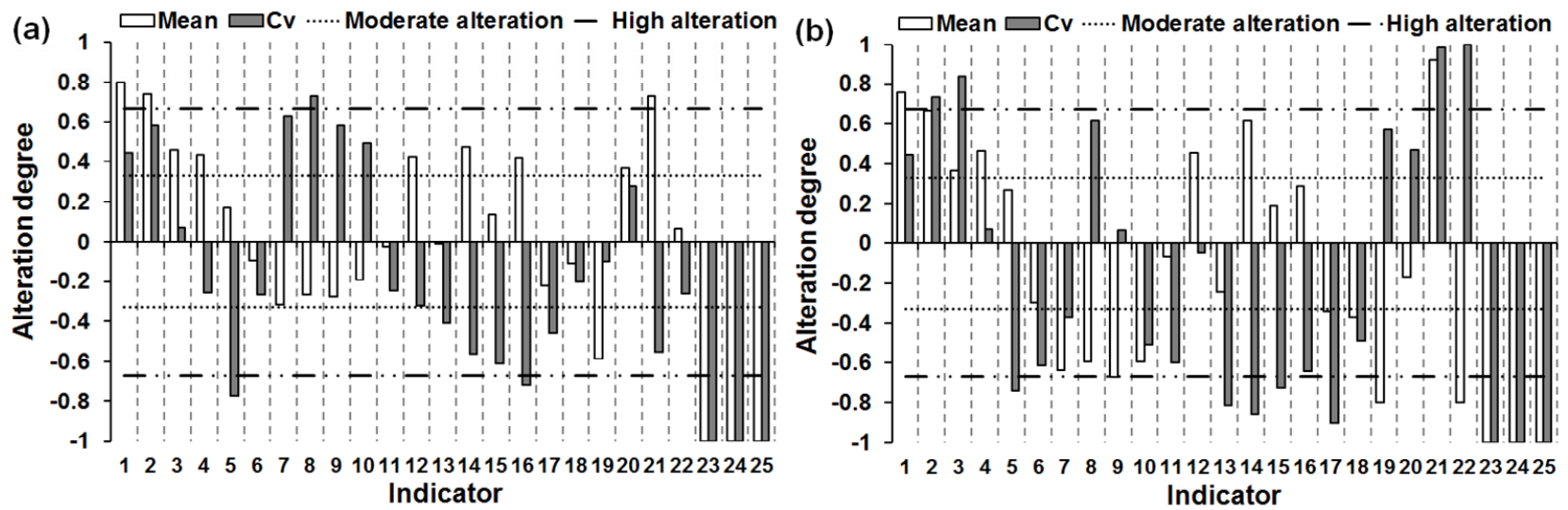

Figure 3. Hydrologic alteration degrees of $25 \mathrm{HHA}$ indicators after reservoir operation at LZH. (a) Alteration degree in post-Liujiaxia period; (b) Alteration degree in post-Longyangxia period.
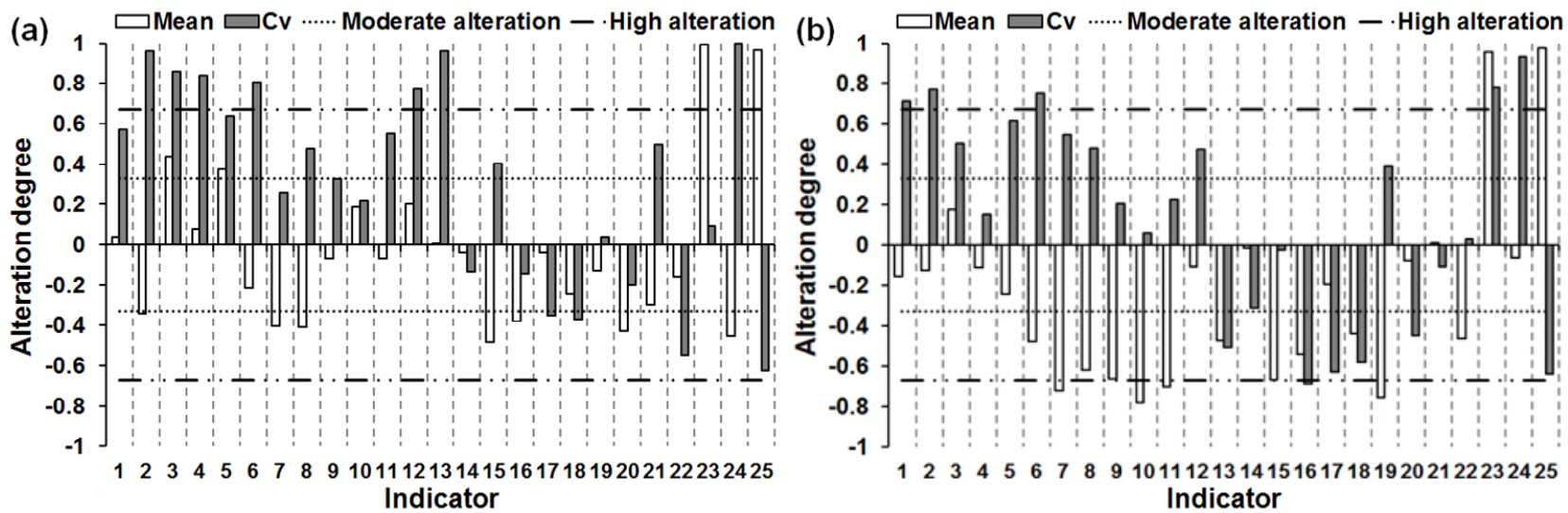

Figure 4. Hydrologic alteration degrees of 25 HHA indicators after reservoir operation at HYK. (a) Alteration degree in post-Sanmenxia period; (b) Alteration degree in post-Xiaolangdi period.

that flood events become more dispersive with the effects of both reservoir storage and natural inflow condition. The mean monthly flows are further reduced during the flood season and further increased during the non-flood seasons. The flood duration is clearly shortened and the frequency is decreased, making the peak clipping effect discernable for the Longyangxia reservoir.

The number of moderate or worse alteration indicators (i.e., $\left|d_{i}^{j}\right|>0.33$ ) increased from 11 during the post-Liujiaxia period to 21 in the joint phase. As expected, the accumulated effects of the reservoirs on the hydrologic regime became more severe as the flow regulation capacity increased by joint operation.

\section{(3) Impacts of Sanmenxia operation}

As shown in Figure 4(a), the Sanmenxia reservoir mainly affects the monthly average flows, making them more dispersed. The average flow of drought events is lower than during the pre-Sanmenxia period, but the duration and frequency increased significantly, indicating that Sanmenxia may cause frequent low-flow conditions. The overall hydrologic alteration caused by Sanmenxia is relatively small because of its low storage capacity and special regulation rules, which is consistent with the assessment of Yang et al. (2008).

(4) Impacts of Sanmenxia-Xiaolangdi joint operation

As shown in Figure 4(b), after Xiaolangdi began functioning, the hydrologic regime of Huanyuankou section changed significantly, especially with the reduction of both the mean monthly flows during the flood season and the flood event indicators. The joint operation of Liujiaxia and Longyangxia has controlled most of the floodwater and altered the flow regime downstream. The regulation capacity for the middownstream was further strengthened after Xiaolangdi was completed. As a result, significant volumes of water are now impounded in the reservoirs, and the related indicators are significantly different, as shown in Figure 4(b).

\subsection{Distribution Features of the Hydrologic Alteration of Flow Events}

Besides less indicators, HHA has an advantage over IHA-RVA in terms of describing flow events by hydrograph. 
Considering the significance of Phase 3 (late 1980s to 2000s), the hydrologic alteration of the mean monthly flow, pulse events, flood events, and drought events in seven sections are shown in Figures 5 to 8.

\section{(1) Mean monthly flow}

As shown in Figure 5(a), the mean monthly flows upstream increased during the non-flood season and decreased during the flood season; however, it decreased from April to June at the midstream sections and decreased for all months at the downstream sections. This decrease in the midstream coincides with the main irrigation period in the Yellow River basin, which is also from April to June. The middle and downstream are influenced by water diversions both for irrigation and cities from reservoirs and river channel. Thus, the changes to the mean monthly flow exhibit a discernable consistency with irrigation water use patterns. Due to the uncertainty of social water diversion, reservoir impounding conditions, and natural inflows, most of the $C v$ degrees of alteration of the monthly average flow at each section are positive, especially during the non-flood season at the downstream sections, as shown in Figure 5(b).

\section{(2) Pulse event}

The degrees of alteration of the high-flow-pulse events in the midstream and downstream are larger than in the upstream and mostly negative because the rising-water season from Ap- ril to June is also the irrigation period for the midstream and downstream, during which rainfall-runoff is relatively low. The decreases in the high flow and flow pulses are mainly due to the significant conflict between the socio-economic water demands and instream flows.

\section{(3) Flood event}

In the upper and middle reaches, the changes in the floodwater characteristics are relatively severe, with decreases in the flood peak, duration, and frequency and increases in the rising and falling rates of floods, which probably close to the operation of the Longyangxia reservoir. In the lower reach, the peak value decreases and the duration is shorter than in the natural state. However, the water condition's rate of change exhibits only slight changes. The degrees of alteration for $C v$ are mostly negative, indicating that the features of flood events are more similar in the post-development period than in the natural state.

\section{(4) Drought event}

Drought events almost disappear in the upstream sections but occur more often and more severely in the middle and lower reaches. Although the large storage capacity and joint operation of the reservoirs in the upper reach can temper the annual flow process, it can further contribute to both water diversion and withdrawal in the middle and lower reaches, which decreases the river flow and increases the low flow
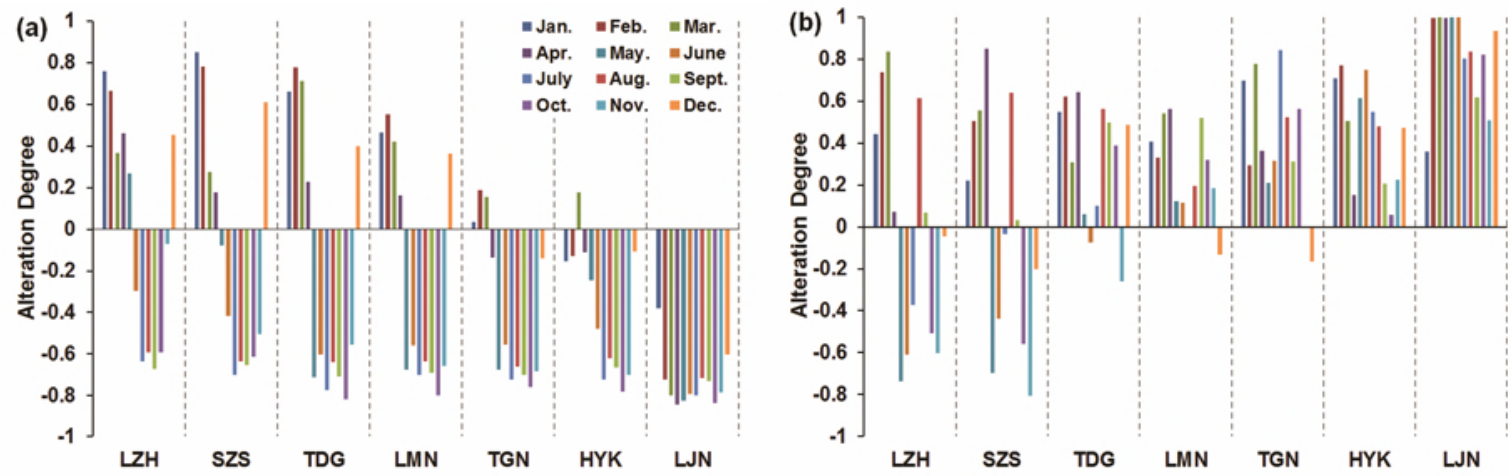

Figure 5. Hydrologic alteration for the mean monthly flows at seven sections in Phase 3 by HHA. (a) Alteration degree of the mean value; (b) Alteration degree of Cv.
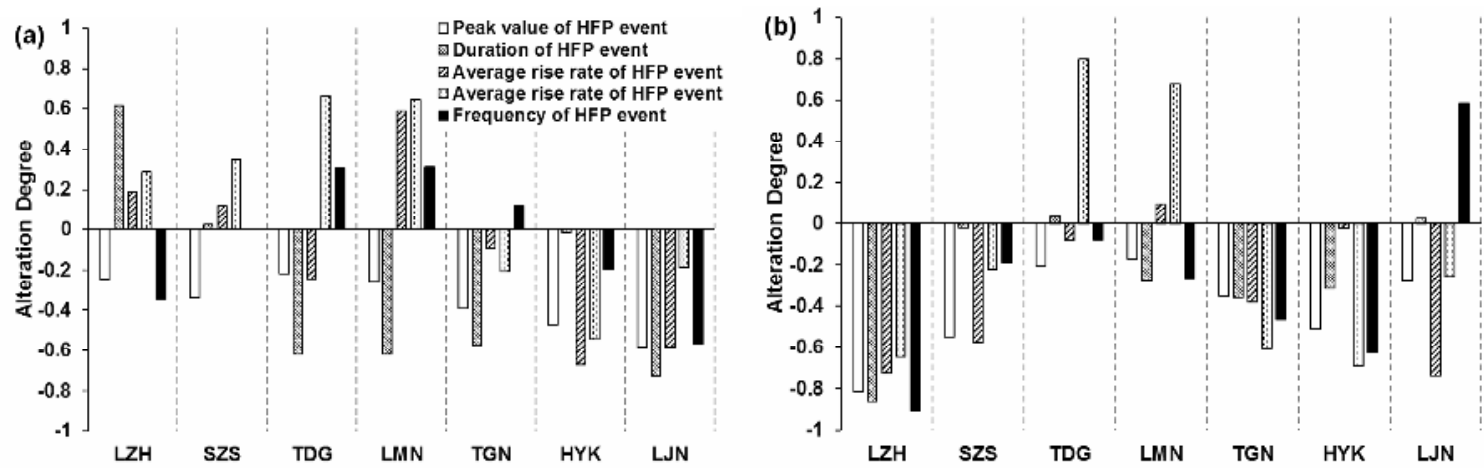

Figure 6. Hydrologic alteration for the pulse events at seven sections in Phase 3 by HHA. (a) Alteration degree of the mean value; (b) Alteration degree of $\mathrm{Cv}$. 
events in the lower reach. This observation suggests that the hydrologic regime is influenced mainly by reservoir regulation but also by the water withdrawal.

\subsection{Overall Hydrologic Alterations in All Sections with HHA and IHA-RVA}

The degrees of alteration of indicators were also calculated using IHA-RVA and compared with the results obtained with HHA. The overall degrees of hydrologic alteration at the sections are represented by the absolute values of the results obtained with these two methods, as shown in Figure 9. The RVA target range used for the analysis is defined by the 25th- and 75th-percentile values of a particular indicator.

(1) The trends related to temporal distribution using these two evaluations are consistent, indicating that the flow regime at each section after the Longyangxia regulation has been altered more significantly. Longyangxia began to store water in 1986. As the only reservoir in the mainstream of the Yellow River with the capacity for multi-year regulation, Longyangxia controls nearly $65 \%$ of the runoff from upstream and is the main source of flood control. After its construction and based on its combined operation with Liujiaxia, Longyangxia's effect has directly altered the annual distribution of water in the upstream region and has exerted a significant influence on the flow regime of the mainstream. Additionally, the operation of Longyangxia creates a gentler hydrologic process throughout the year, which facilitates water diversion for human use and further aggravates the alteration of the flow regime.

(2) The trends related to spatial distribution using these two methods are consistent, indicating that the degree of alteration at sections both upstream and downstream are greater than those occurring midstream. The alteration at the estuary section, LJN, is the most severe. This result can be explained as follows. The major reservoirs are mainly located in the initial part of the upstream and at the lower end of the midstream. Influenced by the regulation of the reservoirs, the upstream flow regime has a relatively large alteration, whereas the midstream flow regime has a relatively small alteration due to the influence of water diversion for human use rather than the direct impact of the major reservoirs. The downstream flow regime exhibits the largest changes, as it is affected by both the reservoir regulation and water diversion, especially at LJN.
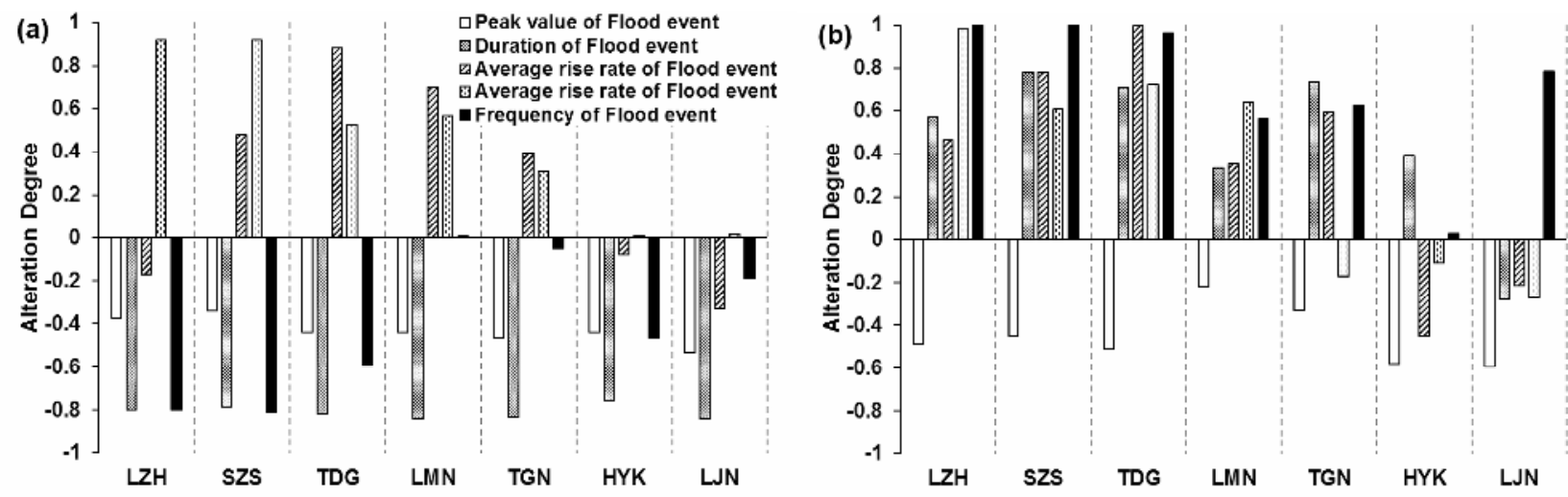

Figure 7. Hydrologic alteration for flood events at seven sections in Phase 3 by HHA. (a) Alteration degree of the mean value; (b) Alteration degree of $\mathrm{Cv}$.
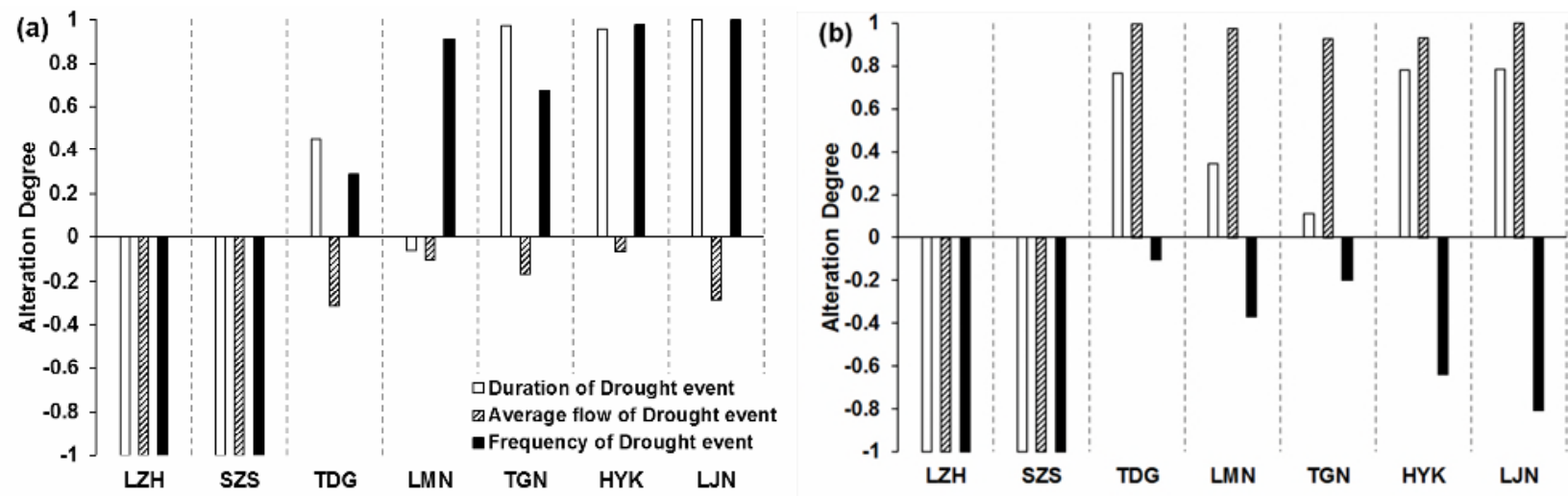

Figure 8. Hydrologic alteration for drought events at seven sections in Phase 3 by HHA. (a) Alteration degree of the mean value; (b) Alteration degree of Cv. 

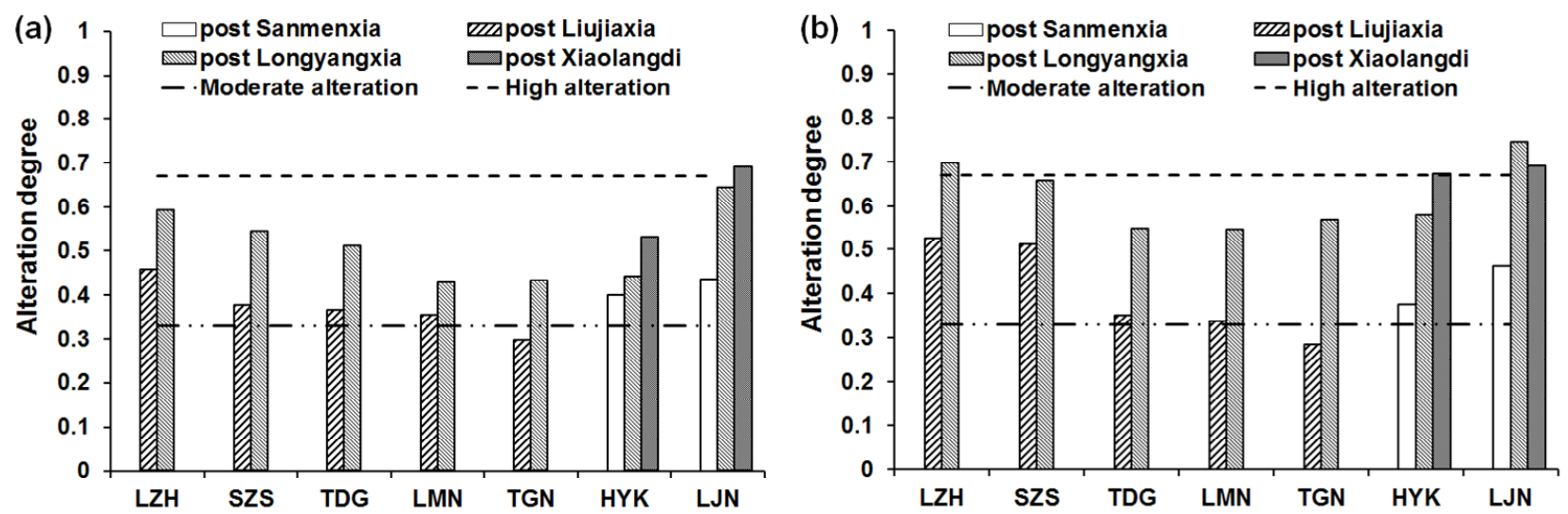

Figure 9. Overall of hydrologic alteration degrees at the seven sections along the main Yellow River in different periods. (a) Results of HHA; (b) Results of IHA-RVA.

Table 6. Degrees of Alteration by IHA-RVA at LJN*

\begin{tabular}{lcc}
\hline Indictor & Phase 3 & Phase 4 \\
\hline 1-day minimum & -1.00 & -0.07 \\
3-day minimum & -1.00 & -0.26 \\
7-day minimum & -1.00 & -0.81 \\
30-day minimum & -1.00 & -1.00 \\
90-day minimum & -0.86 & -1.00 \\
1-day maximum & -1.00 & -1.00 \\
3-day maximum & -1.00 & -1.00 \\
7-day maximum & -1.00 & -1.00 \\
30-day maximum & -1.00 & -1.00 \\
90-day maximum & -1.00 & -1.00 \\
Number of zero days & -0.92 & 0 \\
BFI & -0.86 & 0.11 \\
Date of minimum & 0.53 & 0.67 \\
Date of maximum & 0.11 & -0.63 \\
Low-flow-pulse count & -0.17 & -0.44 \\
Low-flow-pulse duration & 0.07 & -0.05 \\
High-flow-pulse count & -0.31 & -0.44 \\
High-flow-pulse duration & 0.07 & 0.11 \\
Rise rate & -0.86 & -1.00 \\
Fall rate & -0.76 & -1.00 \\
Number of reversals & -0.86 & -0.07 \\
\hline * The degrees of alteration for the monthly flow indicators are \\
provided in Table 8. & & \\
& & \\
\hline
\end{tabular}

(3) It is noticed that the degree of alteration at the lower reach section LJN in Period 3 and Period 4, the trends as evaluated by the two methods are clearly different. The IHA-RVA results indicate that the alteration in the Period 3 is greater than in the Period 4, whereas the HHA results indicate the opposite trend. Analyzing the details in IHA-RVA, the indicators relating to minimums (i.e., one- or three- day minimum, number of zero days, BFI) have smaller alterations in Period 4 than in Period 3, as shown in Table 6, which corresponding to the more dry-up events in Period 3 and no dry-up event after the year 2000 due to the regulation of the Xiaolangdi reservoir. Whereas the details in HHA, the indicators relating to minimums (i.e., duration, average flow and frequency in drought events) have larger alterations in Period 4 than in Period 3, as shown in Table 7, which corresponding the lower average low-flow and longer duration of drought events in Period 4 even though there is no dry-up event. Besides, IHA considers more power for drought by seven out of 33 indicators in describing extreme low events, whereas the HHA only considers three out of 25.

(4) It is also noticed, the IHA-RVA results indicate that the alteration at upper reach $\mathrm{LZH}$ is high with record of 0.7 but HHA shows a moderate alteration with record of 0.6. Due to the biologically relevant attributes of the hydrologic indicators, high ecological degradation would be understood with the high hydrologic alteration. However, the ecological problem in the upper reach of the Yellow River is not serious in reality (Fu et al, 2010). In this case, the IHA-RVA may magnify the actual alteration due to its numerous extreme indictors (14 out of 33 indicators) most focusing on microcosmic, such as the one- and three-day maximum/minimum. Whereas, the HHA are more focusing on summarizing the features of different hydrologic seasons and more macroscopic, thus, it may be more suitable for the upstream region of a large river.

\subsection{Details of the Hydrologic Alterations at $\mathrm{LJN}$ with HHA and IHA-RVA}

In order to show more characteristics of HHA, a more detailed comparison between HHA and IHA-RVA at section of LJN in Period 3, shown in Tables $6 \sim 8$, as an example as below.

(1) The two methods produce similar results with respect to the alterations to monthly flows, as shown in Table 8.

(2) Both the minimum indicators (IHA-RVA) and drought event indicators (HHA) change considerably heavy due to the frequently dry-up drought events.

(3) The high-flow-pulse threshold in IHA is set as the 25th to 75th-percentile daily discharge with static value of $2,000 \mathrm{~m}^{3} / \mathrm{s}$ in the pre-development period at LJN. And the threshold of the high-flow-pulses defined by HHA at LJN is $2,040 \mathrm{~m}^{3} / \mathrm{s}$. Thus, the results are comparable. 
Regarding to the high-flow-pulse duration, the HHA results demonstrate a severe negative alteration $(-0.84$ in Period 3), indicating that the duration is shortened when compared to the reference period (Period 1). In contrast, the IHA-RVA results indicate that the alteration is minor (0.07), suggesting a small change in target range. However, a further calculation by the IHA-RVA, the alteration degree in the other two intervals out of the target range is -1 in the interval above the 75th percentile, and 0.67 in the interval below the 25th percentile. These results indicate that the distribution range of flood duration decreases as a whole, representing a large change in tendency, which is consistent with the HHA results.

Table 7. Degrees of Alteration for the Flow Event Indicators by HHA at LJN

\begin{tabular}{lrrrr}
\hline \multirow{2}{*}{ Indicator } & \multicolumn{3}{c}{ Phase 3 } & Phase 4 \\
\cline { 2 - 5 } & Mean & $\mathrm{Cv}$ & Mean & $\mathrm{Cv}$ \\
\hline Peak value of HFP* events & -0.58 & -0.28 & 0.53 & -0.45 \\
Duration of HFP events & -0.73 & 0.03 & -0.55 & -0.21 \\
Average rise rate of HFP events & -0.59 & -0.74 & 0.17 & -0.01 \\
Average fall rate of HFP events & -0.19 & -0.26 & -0.78 & -0.55 \\
Frequency of HFP events & -0.57 & 0.58 & -0.70 & 0.81 \\
Peak value of flood events & -0.53 & -0.60 & -0.53 & -0.73 \\
Duration of flood events & -0.84 & -0.28 & -0.83 & -0.17 \\
Average rise rate of flood events & -0.33 & -0.21 & -0.72 & 0.21 \\
Average fall rate of flood events & 0.02 & -0.27 & -0.51 & -0.46 \\
Frequency of flood events & -0.19 & 0.78 & -0.50 & 0.70 \\
Duration of drought events & 1.00 & 0.78 & 1.00 & 0.80 \\
Average flow of drought events & -0.29 & 1.00 & -0.01 & 0.96 \\
Frequency of drought events & 1.00 & -0.81 & 1.00 & -0.81 \\
\hline * HFP refers to high flow pulse, here and below. & &
\end{tabular}

Table 8. Degrees of Alteration for the Monthly Flow Indicators at LJN

\begin{tabular}{|c|c|c|c|c|c|c|}
\hline \multirow{3}{*}{ Month } & \multicolumn{4}{|l|}{ HHA } & \multicolumn{2}{|c|}{ IHA-RVA } \\
\hline & \multicolumn{2}{|c|}{ Phase 3} & \multicolumn{2}{|c|}{ Phase 4} & \multirow[t]{2}{*}{ Phase 3} & \multirow[t]{2}{*}{ Phase 4} \\
\hline & Mean & $\mathrm{Cv}$ & Mean & $\mathrm{Cv}$ & & \\
\hline January & -0.38 & 0.36 & -0.61 & 0.68 & -0.03 & -0.63 \\
\hline February & -0.72 & 0.99 & -0.80 & 0.89 & -0.72 & -1.00 \\
\hline March & -0.80 & 1.00 & -0.84 & 0.93 & -1.00 & -1.00 \\
\hline April & -0.84 & 1.00 & -0.86 & 0.98 & -1.00 & -1.00 \\
\hline May & -0.82 & 1.00 & -0.78 & 0.99 & -0.86 & -0.81 \\
\hline June & -0.79 & 1.00 & -0.25 & 0.97 & -0.58 & -0.81 \\
\hline July & -0.80 & 0.80 & -0.77 & 0.73 & -1.00 & -1.00 \\
\hline August & -0.72 & 0.84 & -0.84 & 1.00 & -0.72 & -1.00 \\
\hline September & -0.73 & 0.62 & -0.83 & 0.99 & -0.86 & -0.81 \\
\hline October & -0.84 & 0.82 & -0.75 & 0.98 & -1.00 & -0.63 \\
\hline November & -0.78 & 0.51 & -0.76 & 0.93 & -1.00 & -0.63 \\
\hline December & -0.60 & 0.93 & -0.71 & 0.98 & -0.44 & -0.81 \\
\hline
\end{tabular}

The conclusions above suggest that IHA-RVA, which only considers the degree of alteration of frequency in the target range, may not always be effective. It is difficult to judge whether the value of an indicator is larger or smaller than its value in the natural state unless additional informa- tion is combined. In contrast, the results of the HHA method are easier to understand, representing the degree of alteration and its tendency. Additionally, these results may serve as a guide for regulation practices designed to recover the characteristics of a river's natural flow regime.

The high flow pulse during the rising-water season is evaluated through HHA, whereas this flow period is not specifically considered in IHA. The results demonstrate that the indicators for the high flow pulse change moderately, with the peak, frequency and the rise rate decreasing that means the high-flow-pulses becoming more stable during the risingwater season.

\section{Conclusions}

In this paper, a hydrograph-based hydrologic alteration assessment method (HHA) is proposed and applied to the mainstream of the Yellow River to understand the alteration of the hydrologic regime by human activities, primarily as a result of reservoir operation. With the assessments and comparison between HHA and IHA-RVA, following conclusions can be derived:

(1) The hydrologic alterations at all sections are notable. Most of changes are in moderate level and LZH (by IHA) and LJN (by IHA and HHA) are in large level that means the alteration in the midstream is smaller than in the upstream or downstream which is considered as no huge reservoir in this reaches. An overall reduction of peak value, duration and diversity of high-flow-pulse events and flood events is observed. The drought events looks disappeared in the upper reach but are more severe in the middle and lower reaches, and the largest degree of hydrologic alteration is at LJN, that is considered as the result of human factors accumulated in the lower reach,.

(2) All the four reservoirs have the impacts on river hydrological graph and flow events. Regarding to the alteration at sections and impacts of reservoirs, the closer up to reservoir the larger changes, the larger storage the heavier impacts. The Longyangxia has the greatest impact on the Yellow River mainstream, and Sanmenxia has a relatively smaller influence. The alteration of the hydrologic regime caused by joint reservoir operation is much greater than the alteration caused by single reservoir operation. A sound reservoir regulation rule is needed to guarantee the environmental flows at right time with proper discharge.

(3) Both IHA and HHA are functional in assessment changes of environment flow. The HHA is based on a biorelated hydrograph pattern and can present a set of more detailed and visual results to diagnose the alteration in each flow season, which is benefit to understand the trends and guide improving reservoir regulation rule for environmental flow. Besides, the assessment results for larger flow in larger river, as at LZH section in the Yellow River, are more aceptable. Despite all these, there are still some bugs need to be overcome in HHA, such as to define the standard bio-related hydrograph pattern for particular river, and not sensitive 
enough to extreme flow events especially in zero flow events at lower reach as at LJN section in the Yellow River.

Hydrologic regime alterations caused by indirect artificial perturbations, such as climate change or underlying surface conditions, are beyond the scope of the current paper. The hydrologic influence of climatic and other indirect factors will need to be distinguished and quantified in the future. In addition, eco-hydrologic mechanism studies and quantitative research on the ecological systems influenced by hydrologic regime changes should be performed to strengthen ecosystem monitoring.

Acknowledgments. The work described in this paper was financially supported by the National Natural Science Foundation of China (50979040), the National Technology Support Project of China (2006BAB14B01), and the Australia-China Environment Development Partnership (P0018).

\section{References}

Assani A.A., Quessy J.F., Mesfioui M, and Matteau M. (2010). An example of application: The ecological "natural flow regime" paradigm in hydroclimatology. Adv. Water Resour., 33, 537-545. http:// dx.doi.org/10.1016/j.advwaters.2010.02.005.

Bashir, Z.A., and El-Hawary, M.E. (2009). Applying wavelets to short-term load forecasting using PSO-based neural networks. IEEE Trans. Power Syst., 24(1), 20-27. http://dx.doi.org/10.1109/ TPWRS.2008.2008606

Bayley, P.B. (1988). Factors affecting growth rates of young tropical floodplain fishes: seasonality and density-dependence. Environ. Biol. Fishes, 21(2), 127-142. http://dx.doi.org/10.1007/BF000048 48

Bejarano, M.D., Marchamalo, M., García de Jalón, D., and González del Tánago, M. (2010). Flow regime patterns and their controlling factors in the Ebro basin (Spain). J. Hydrol., 385(1-4), 323-335. http://dx.doi.org/10.1016/j.jhydrol.2010.03.001

Black, A.R., Rowan, J.S., Duck, R.W., Bragg, O.M., and Clelland, B.E. (2005). DHRAM: a method for classifying river flow regime alterations for the EC Water Framework Directive. Aquat. Conserv.: Mar. Freshw. Ecosyst., 15(5), 427-446. http://dx.doi.org/10.1002/a qc.707

Bunn, S.E., and Arthington, A.H. (2002). Basic principles and ecological consequences of altered flow regimes for aquatic biodiversity. Environ. Manage., 30(4), 492-507. http://dx.doi.org/10.10 07/s00267-002-2737-0

Carlisle, D.M., Falcone, J., Wolock, D.M., Meador, M.R., and Norris, R.H. (2010) Predicting the natural flow regime: models for assessing hydrological alteration in streams. River Res. Appl., 26(2), 118-136. http://dx.doi.org/10.1002/rra.1247

Chang, F.J., Tsai, M.J., Tsai, W.P., and Herricks, E.E. (2008). Assessing the ecological hydrology of natural flow conditions in Taiwan. J. Hydrol., 354(1), 75-89. http://dx.doi.org/10.1016/j.jhy drol.2008.02.022

Chang, F.J., Wu, T.C., Tsai, W.P., and Herricks, E.E. (2009). Defining the ecological hydrology of Taiwan Rivers using multivariate statistical methods. J. Hydrol., 376(1), 235-242. http://dx.doi.org/1 0.1016/j.jhydrol.2009.07.034

Chen, M.J., Feng, H.L., Wang, L.Q., Wang, G.X., and Huang, C.S. (2006). Scientific regulation and management based on ecological flow regime. Adv. Water Resour., 17(5), 631-636. (in Chinese)

Choi, S.U., Yoon, B., and Woo, H. (2005). Effects of dam - induced flow regime change on downstream river morphology and vegetation cover in the Hwang River, Korea. River Res. Appl., 21, 315-325. http://dx.doi.org/10.1002/rra.849

Kurup, P.U., and Dudani, N.K. (2002). Neural networks for profiling stress history of clays from PCPT data. J. Geotech. Geoenviron. Eng., 128(7), 569-579. http://dx.doi.org/10.1061/(ASCE)1090-02 41(2002)128:7(569)

Fu, X.C, Ye, L., Xu, Y.Y., and Cai, Q.H. (2010). Survey of water quality and benthos in the Yellow River Basin. J. Ecol. Sci., 29(1), 1-7 (in Chinese)

Galat, D.L., and Lipkin, R. (2000). Restoring ecological integrity of great rivers: historical hydrographs aid in defining reference conditions for the Missouri River. Hydrobiologia, 422, 29-48. http://dx. doi.org/10.1023/A:1017052319056

Gippel, C.J. (2001). Hydrological analyses for environmental flow assessment. Proc. MODSIM, 2001, 873-880.

Gippel, C.J., Jiang, X.H., Zhang, D., Cooling, M., Kerr, G., Close, P., Jin, S.Y., Li, L.T., Wang, Z.J., Ma, Z.Z., Wang, L., Sun, Y.B., Pang, H., Song, R.P, Sun, F., Shang, H.Q., and Speed, R. (2011). Environmental flows assessment for the Lower Yellow River. International WaterCentre, Brisbane, Australia. http://www.water centre.org/research/rhef/attachments/technical-reports/yellow-river -eflows-report (accessed Sept. 22 2012).

Gordon, N.D., McMahon, T.A., Finlayson, B.L., Gippel, C.J., and Nathan, R.J. (2004). Stream Hydrology: An Introduction for Ecologists. Second Edition, John Wiley \& Sons, Chichester.

Growns, J., and Marsh, N. (2000). Characterisation of flow in regulated and unregulated streams in eastern Australia. Cooperative Research Centre for Freshwater Ecology Technical Report 3.

Hamed, M.M., Khalafallah, M.G., and Hassanien, E.A. (2004). Prediction of wastewater treatment plant performance using artificial neural networks. Environ. Model. Software, 19(10), 919-928. http://dx.doi.org/10.1016/j.envsoft.2003.10.005

Hu, W.W., Wang, G.X., Deng, W., and Li, S.N. (2008). The influence of dams on ecohydrological conditions in the Huaihe River basin, China. Ecol. Eng., 33(3), 233-241. http://dx.doi.org/10.1016/j.eco leng.2008.04.003

Jiang, X.H., Arthington, A., and Liu, C.M. (2010). Environmental flow requirements of fish in the lower reach of the Yellow River. Water Int., 35(4), 381-396. http://dx.doi.org/10.1080/02508060.20 10.506261

Junk, W.J., Bayley, P.B., and Sparks, R.E. (1989). The Flood pulse Concept in River-floodplain Systems. Canadian Special Publications in Fisheries and Aquatic Sciences, 106, 110-127.

Kim, B.S., Kim, B.K., and Kwon, H.H. (2011). Assessment of the impact of climate change on the flow regime of the Han River basin using indicators of hydrologic alteration. Hydrol. Process., 25(5), 691-704. http://dx.doi.org/10.1002/hyp.7856

Lin, C.W., and Wang, J.S. (2008). A Digital Circuit Design of Hyperbolic Tangent Sigmoid Function for Neural Networks. Circuits and Systems, ISCAS 2008, 856-859. http://dx.doi.org/10.110 9/ISCAS.2008.4541553

Liu, C.M., and Zhang, S.F. (2002). Drying up of the Yellow River: its impacts and counter-measures. Mitigation Adapt. Strat. Global Change, 7(3), 203-214. http://dx.doi.org/10.1023/A:1024408310 869

Lytle, D.A., and Poff, N.L. (2004). Adaptation to natural flow regimes. Trends Ecol. Evol., 19(2), 94-100. http://dx.doi.org/10.10 16/j.tree.2003.10.002

Magilligan, F.J., and Nislow, K.H. (2005). Changes in hydrologic regime by dams. Geomorphology, 71(1), 61-78. http://dx.doi.org/ 10.1016/j.geomorph.2004.08.017

Malinova, T., and Guo, Z.X. (2004). Artificial neural network modelling of hydrogen storage properties of Mg-based alloys. Mater. Sci. Eng., 365(1), 219-227. http://dx.doi.org/10.1016/j.msea. 
2003.09.031

Naiman, R.J., Latterell, J.J., Pettit, N.E., and Olden, J.D. (2008). Flow variability and the biophysical vitality of river systems. C. $R$. Geosci., 340(9), 629-643. http://dx.doi.org/10.1016/j.crte.2008.0 1.002

Olden, J.D., and Poff, N.L. (2003). Redundancy and the choice of hydrologic indices for characterizing streamflow regimes. River Res. Appl., 19(2), 101-121. http://dx.doi.org/0.1002/rra.700.

Opperman, J.J., Luster, R., McKenney, B.A., Roberts, M., and Meadows, A.W. (2010).Ecologically Functional Floodplains: Connectivity, Flow Regime, and Scale. J. Am. Water Resour. Assoc., 46(2), 211-226. http://dx.doi.org/10.1111/j.1752-1688.2010.0042 6.X

Pegg, M.A., Pierce, C.L., and Roy, A. (2003). Hydrological alteration along the Missouri River basin: a time series approach. Aquat. Sci. Res. Bound., 65(1), 63-72. http://dx.doi.org/10.1007/s000270300 005

Poff, N.L., Allan, J.D., Bain, M.B., Karr, J.R., Prestegaard, K.L., Richter, B.D., Sparks, R.E., and Stromberg, J.C. (1997). The natural flow regime. BioScience, 47(11), 769-784. http://dx.doi.org/10. 2307/1313099

Richter, B.D., Baumgartner, J.V., Powell, J., and Braun, D.P. (1996). A method for assessing hydrologic alteration within ecosystems. Conserv. Biol., 10(4), 1163-1174. http://dx.doi.org/10.1046/j.15 23-1739.1996.10041163.x

Richter, B., Baumgartner, J., Wigington, R., and Braun, D. (1997). How much water does a river need? Freshw. Biol., 37(1), 231-249. http://dx.doi.org/10.1046/j.1365-2427.1997.00153.x

Richter, B.D., Baumgartner, J.V., Braun, D.P., and Powell, J. (1998). A spatial assessment of hydrologic alteration within a river network. Regul. Rivers: Res. Manage., 14(4), 329-340. http://dx. doi.org/10.1002/(SICI)1099-1646(199807/08)14:4<329::AID-RR R505>3.3.CO;2-5

Richter, B.D., Mathews, R., Harrison, D.L., and Wigington, R. (2003). Ecologically sustainable water management: managing river flows for ecological integrity. Ecol. Appl., 13(1), 206-224. http://dx.doi. org/10.1890/1051-0761(2003)013[0206:ESWMMR]2.0.CO;2

Richter, B.D., Warner, A.T., Meyer, J.L., and Lutz, K. (2006). A collaborative and adaptive process for developing environmental flow recommendations. River Res. Appl., 22(3), 297-318. http://dx. doi.org/10.1002/rra.892

Richter, B.D., and Thomas, G.A. (2007). Restoring environmental flows by modifying dam operations. Ecol. Soc., 12(1), 12. http:// www.ecologyandsociety.org/vol12/iss1/art12/ (accessed Mar 24, 2011).

Shiau, J.T., and Wu, F.C. (2004). Feasible diversion and instream flow release using range of variability approach. J. Water Resour. Plann. Manage., 130, 395. http://dx.doi.org/10.1061/(ASCE)073 3-9496(2004)130:5(395)

Shiau, J.T., and Wu, F.C. (2008). A histogram matching approach for assessment of flow regime alteration: application to environmental flow optimization. River Res. Appl., 24, 914-928. http://dx.doi.or g/10.1002/rra.1102

Stanford, J.A., Ward, J.V., Liss, W.J., Frissell, C.A., and Williams, R.N. (1996). A general protocol for restoration of regulated rivers. Regul. Rivers: Res. Manage., 12(4-5), 391-413. http://dx.doi.org/1 0.1002/(SICI)1099-1646(199607)12:4/5<391::AID-RRR436>3.0. $\mathrm{CO} ; 2-4$

Suen, J.P. (2006). Ecologically based methods for multi-objective water resources management in Taiwan, University of Illinois at Urbana-Champaign, Urbana, Illinois, USA.

Wu, B.S., Wang, G.Q., Xia, J.Q., Fu, X.D., and Zhang, Y.F. (2008). Response of bankfull discharge to discharge and sediment load in the Lower Yellow River. Geomorphology, 100(3), 366-376. http:// dx.doi.org/10.1016/j.geomorph.2008.01.007

Yang, Y.E., Cai, X.M., and Herricks, E.E. (2008). Identification of hydrologic indicators related to fish diversity and abundance: A data mining approach for fish community analysis. Water Resour. Res., 44(4), W04412. http://dx.doi.org/10.1029/2006WR005764

Yang, T., Zhang, Q., Chen Y.D., Tao, X., Xu, C.Y., and Chen, X. (2008). A spatial assessment of hydrologic alteration caused by dam construction in the middle and lower Yellow River, China. Hydrol. Process., 22(18), 3829-3843. http://dx.doi.org/10.1002/hy p.6993

Yang, Z.F, Yan, Y., and Liu, Q. (2011). Assessment of the flow regime alterations in the Lower Yellow River, China. Ecological Informatics. http://dx.doi.org/10.1016/j.ecoinf.2011.10.002

YRCC. (2000). Engineering layout of the mainstream and controlling key project planning, YRCC website. http://www.yellowriver.gov. cn/ (accessed Feb 10, 2011, in Chinese).

Zhang, H.B. (2009). Study on eco-hydrological effect and reservoir ecological regulation on the main Yellow River, Xi'an University of Technology, Xi'an, Shanxi, China (in Chinese). 